\title{
Comparison of basic features and origins of oolitic shoal reservoirs between carbonate platform interior and platform margin locations in the Lower Triassic Feixianguan Formation of the Sichuan Basin, southwest China
}

\author{
Tan Xiuchengi, 2*, Zhao Luzi ${ }^{3}$, Luo Bing ${ }^{4}$, Jiang Xingfu', Cao Jian ${ }^{6}$, Liu \\ Hong $^{2}$, Li Ling ${ }^{2}$, Wu Xingbo ${ }^{2}$ and Nie Yong ${ }^{2}$ \\ ${ }^{1}$ State Key Laboratory of Oil and Gas Geology and Exploitation, Southwest Petroleum University, Chengdu, Sichuan \\ 610500, China \\ ${ }^{2}$ School of Resource and Environment, Southwest Petroleum University, Chengdu, Sichuan 610500, China \\ ${ }^{3}$ Branch of Exploration Management, PetroChina Southwest Oil and Gas Field Company, Chengdu, Sichuan 610051, China \\ ${ }^{4}$ Branch Station in Research Institute of Petroleum Exploration and Development, Post-doctoral Workstation of PetroChina \\ Southwest Oil and Gas Field Company, Chengdu, Sichuan 610051, China \\ ${ }^{5}$ Branch of Exploration Industry, PetroChina Southwest Oil and Gas Field Company, Chengdu, Sichuan 610051, China \\ ${ }^{6}$ Department of Earth Sciences, Nanjing University, Jiangsu 210093, China
}

(C) China University of Petroleum (Beijing) and Springer-Verlag Berlin Heidelberg 2012

\begin{abstract}
The oolitic shoal reservoirs of the Lower Triassic Feixianguan Formation carbonates in the Sichuan Basin of southwest China are an important target for gas exploration in the basin. Their occurrence, like other cases worldwide, can be divided into two locations in general, i.e., platform interior and platform margin locations. Their differences of reservoir features and origins, however, have not been investigated comprehensively due to different exploration degrees. This issue is addressed in this paper, to provide basic data and information for the basin's hydrocarbon exploration and for the study of carbonate platform sedimentology and reservoir geology worldwide. We compared the features of these two types of reservoirs in detail, including the depositional and diagenetic features, pore types and petrophysical features. Based on the comparison, the origin of the reservoirs was further discussed. It is shown that the reservoirs in platform interior and platform margin locations differ significantly. The interior carbonates were deposited in moderate to high energy settings and the dominant lithologic type was limestone, which was weakly compacted and intensely cemented and has undergone meteoric dissolution. Pore types include intragranular dissolution and moldic pores, with low porosities $(<6 \%)$ and low permeabilities $(<0.1 \mathrm{mD})$. By contrast, the platform margin carbonates were deposited in relatively high energy settings and mainly consisted of dolostones with some limestones. The rocks were strongly compacted but incompletely cemented. As a result, some primary intergranular pores were preserved. Both meteoric solution and burial solution have taken place. There are various types of pore spaces including intergranular and intercrystalline solution pores and residual intergranular pores. This type of reservoir generally has better petrophysical properties ( $>9 \%$ porosity and $>0.1 \mathrm{mD}$ permeability) and pore-throat structures than the interior reservoirs. These differences were influenced by both primary depositional features and secondary diagenesis. For the interior carbonate reservoirs, early meteoric dissolution, weak compaction and strong cementation are important controlling factors. By contrast, the factors controlling the formation of the margin carbonate reservoirs mainly include dolomitization, preservation of primary pores and burial dissolution.
\end{abstract}

Key words: Carbonate platform, oolitic shoal reservoir, platform margin, platform interior, Lower Triassic, Feixianguan Formation, Sichuan Basin, China

*Corresponding author. email: tanxiucheng70@163.com Received September 7, 2011

\section{Introduction}

Oolitic shoal reservoirs are an important reservoir type in carbonate hydrocarbon exploration and exploitation with 
many successful cases worldwide (Fan, 2005; Zhao et al, 2007; Luo et al, 2008; Ma et al, 2011), such as the Jurassic Smackover Formation in Arkansas, USA (Bliefnick and Kaldi, 1996), the Jurassic Manusela Formation of Indonesia's Seram Island (Carnell and Wilson, 2004), the upper part of the Middle Triassic Muschelkalk Formation in Europe (Schauer and Aigner, 1997; Borkhataria et al, 2005), the Albian Pinda Formation in Angola (Eichenseer et al, 1999) and the Lower Triassic Feixianguan Formation of the Sichuan Basin in southwest China (Wei et al, 2004; Ma et al, 2005; 2007; Wang et al, 2007; 2008; Guo, 2010). In general, the reservoirs can be divided into two types according to their relative locations on the carbonate platform (Ronchi et al, 2010), i.e., platform interior and platform margin oolitic shoal reservoirs. Previous studies have indicated that the reservoir features vary largely between the two types of reservoirs, thereby leading to different exploration strategies. Understanding the differences is a key to hydrocarbon exploration.

The oolitic shoal reservoirs of the Lower Triassic Feixianguan Formation in the Sichuan Basin of southwest China have been an important target of hydrocarbon (especially gas) exploration of the basin for several decades (Wei et al, 2004; Ma et al, 2005; 2007; Wang et al, 2007; 2008). The proven recoverable gas reserves are approximately several hundred billions of cubic meters (Zhao et al, 2006; Wang et al, 2007). Natural gas has been discovered in both platform interior and platform margin locations (Wang et al, 2008; Wei et al, 2009) (Fig. 1). Of the two locations, the Naxi, Fuchengzhai, Bandong, Huangcaoxia and HebaochangJieshichang fields are located in platform interior areas (Wei et al, 2004; Wang et al, 2008; Luo et al, 2009). By contrast,

the Tieshannan, Tieshanpo, Dukouhe, Luojiazhai, Puguang and Longgang fields are located in platform margin areas (Ran et al, 2005; Ma et al, 2005; Wang et al, 2008). Comparatively, the platform margin reservoirs have better petrophysical properties than the platform interior reservoirs in general. Thus, large to very large gas fields have been found mostly in the platform margin areas, e.g., the Puguang gas field (Ma et al, 2005). Therefore, research attention has been focused on the platform margin reservoirs, including reservoir features (Yang et al, 2006; Ma et al, 2007), diagenesis (Su et al, 2004; Wang et al, 2007; Zhang and $\mathrm{Hu}, 2008$ ) and controlling factors of reservoir distribution and development (Yang et al, 2006; Wang et al, 2008). By contrast, fewer studies have been conducted on the platform interior reservoirs due to relatively poor exploration results (Wei et al, 2004; Luo et al, 2009). However, the platform interior reservoirs can also develop large gas fields, such as the Mississippian reservoirs of USA, which cover an area of approximately $2 \times 10^{6} \mathrm{~km}^{2}$ with both oil and gas having been produced (Keith and Zuppann, 1993; Westphal et al, 2004).

Therefore, to expand the hydrocarbon exploration field in the Sichuan Basin and provide references for the study of carbonate platform sedimentology and reservoir geology worldwide, the differences between the platform interior and platform margin reservoirs in the Sichuan Basin should be studied. However, this has not been thoroughly covered in previous works, although depositional and reservoir features of the two types of reservoirs have been investigated to varying degrees (Zhao et al, 2005). In this paper, we conducted such a comparison of basic reservoir features and origins in detail.

(b)
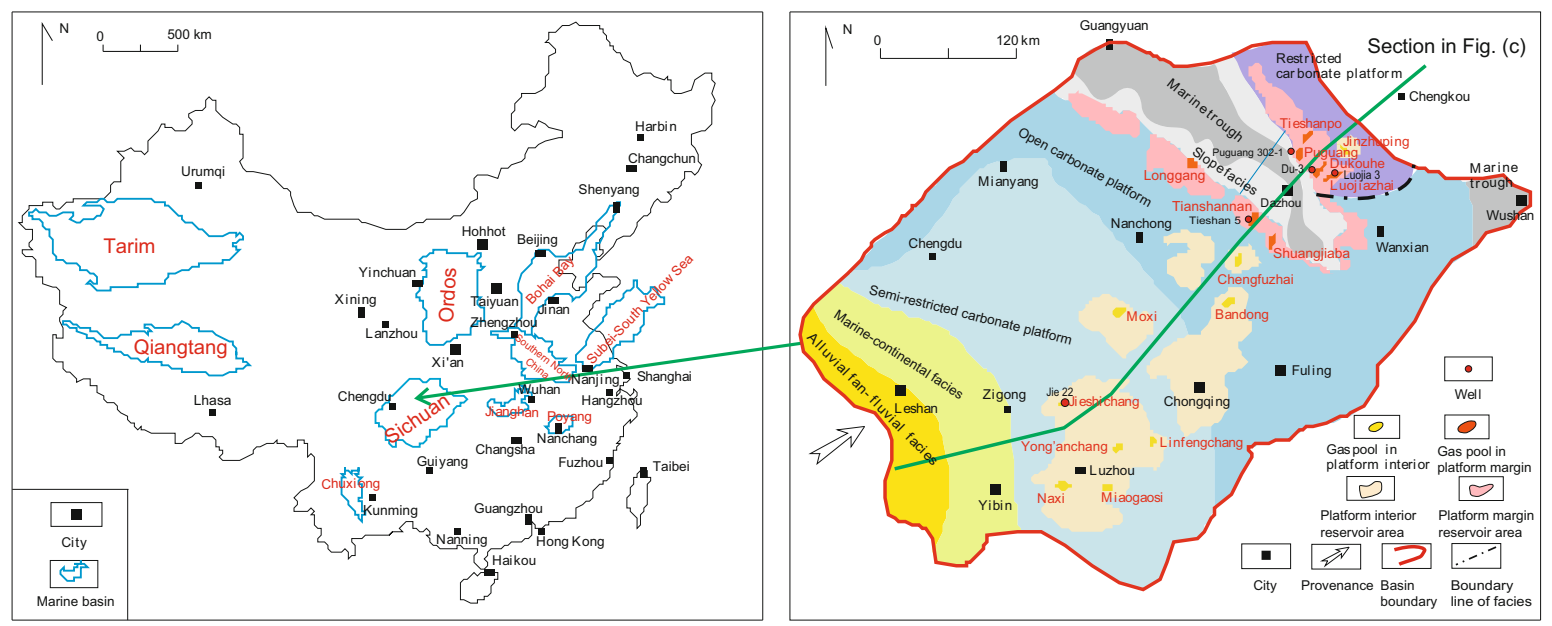

(c)

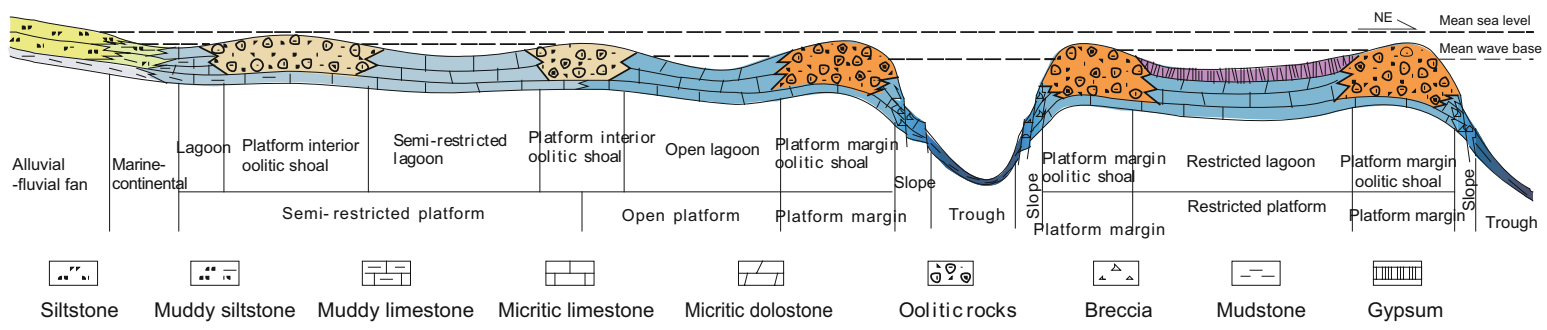

Fig. 1 (a) Ten major marine basins in onshore China and the location of the Sichuan Basin. (b) Sketch map showing the general depositional setting during the Early Triassic Feixianguan period in the Sichuan Basin (modified after Wang et al, 2007). (c) Sketch depositional model during the Early Triassic Feixianguan period in the Sichuan Basin 


\section{Geological setting}

The Sichuan Basin is located in Sichuan Province, southwest China, covering an area of approximately $1.8 \times 10^{5}$ $\mathrm{km}^{2}$ (Tong, 1992) (Fig. 1(a)). In the studied Lower Triassic Feixianguan Formation, its deposition is characterized by a gradual facies transition from the west to the east (Fig. 1(b)). In the western areas, alluvial to fluvial clastics occur widely, being mainly derived from the Kangdian oldland and Longmen Mountains island arc. To the east, there is a mixed deposition of carbonate and clastic rocks, which was deposited under marine-continental facies (Wei et al, 2004; Chen, 2007). Eastward, carbonates are present, and they occur mainly in the eastern and northern basin (Wei et al, 2004; Ma et al, 2005; 2007; Wang et al, 2007; 2008). Of the carbonates, the oolitic shoal rocks are one of the important rock types.

The Early Feixianguan period is characterized by a clear depositional differentiation between deep trough and shallow platform facies in the northeast basin (Wei et al, 2004; Wang et al, 2008) (Fig. 1(b)), leading to the development of two types of oolitic shoals, i.e., platform interior and platform margin shoals (Fig. 1(c)). This is because of a rapid basement subsidence that mainly took place in the Kaijiang and Liangping areas during the Middle to Late Permian period (Wei et al, 2004; Wang et al, 2008). For the two types of shoals, the platform interior shoals mainly occur in the center and east of the basin with a sheet-like lateral distribution (Wei et al, 2004; Luo et al, 2009) (Figs. 1(b) and 1(c)). By contrast, the platform margin shoals mainly occur in the northeast basin surrounding the Kaijiang-Liangping trough areas with a beaded to banded distribution (Ma et al, 2005; 2007; Yang et al, 2006; Chen, 2007) (Figs. 1(b) and 1(c)). Effective reservoirs have been found in both types of shoals (Ran et al, 2005; Wei et al, 2004; 2009; Ma et al, 2005; Wang et al, 2008). The gas produced from the Lower Triassic Feixianguan Formation is mainly sourced from Upper Permian coal- bearing mudstones with likely part contribution from the Lower Triassic carbonates (Zhao et al, 2006). The overlying Lower and Middle Triassic evaporites and evaporitic tight carbonates act as cap rocks (Zhao et al, 2006).

\section{Comparison of basic features of oolitic shoal reservoirs between platform interior and platform margin locations}

Differences of basic features of oolitic shoal reservoirs between the platform interior and platform margin locations can be mainly divided into four categories; depositional features, diagenesis, pore types and petrophysical features.

\subsection{Depositional features}

Depositional features include the mineralogical composition of carbonate rocks, structure and thickness of the reservoir bodies and the position of the reservoir development.

\subsubsection{Platform interior reservoirs}

The rocks in platform interior reservoirs are mainly composed of oolitic limestones deposited in shallow water environments with high energy. The proportion of oolites generally ranges between $50 \%$ and $85 \%$, dominated by individual oolites. The oolites are commonly $0.2-1.0 \mathrm{~mm}$ in size. Interparticle spaces are generally filled with two to three generations of sparry calcites with minor micritic carbonate cements. Little dolomitization is observed (Fig. 2).

Depositional features include shallowing- and coarseningupward cycles. Reverse graded bedding is common. The thickness of individual shoal bodies is generally less than 2 $\mathrm{m}$. The reservoir space is commonly developed at the top of single shallowing-upward sequence (Luo et al, 2009) (Fig. 2) and mainly consists of secondary pores (in particular intragranular dissolution and moldic pores) with part primary pores (Fig. 3(a)).

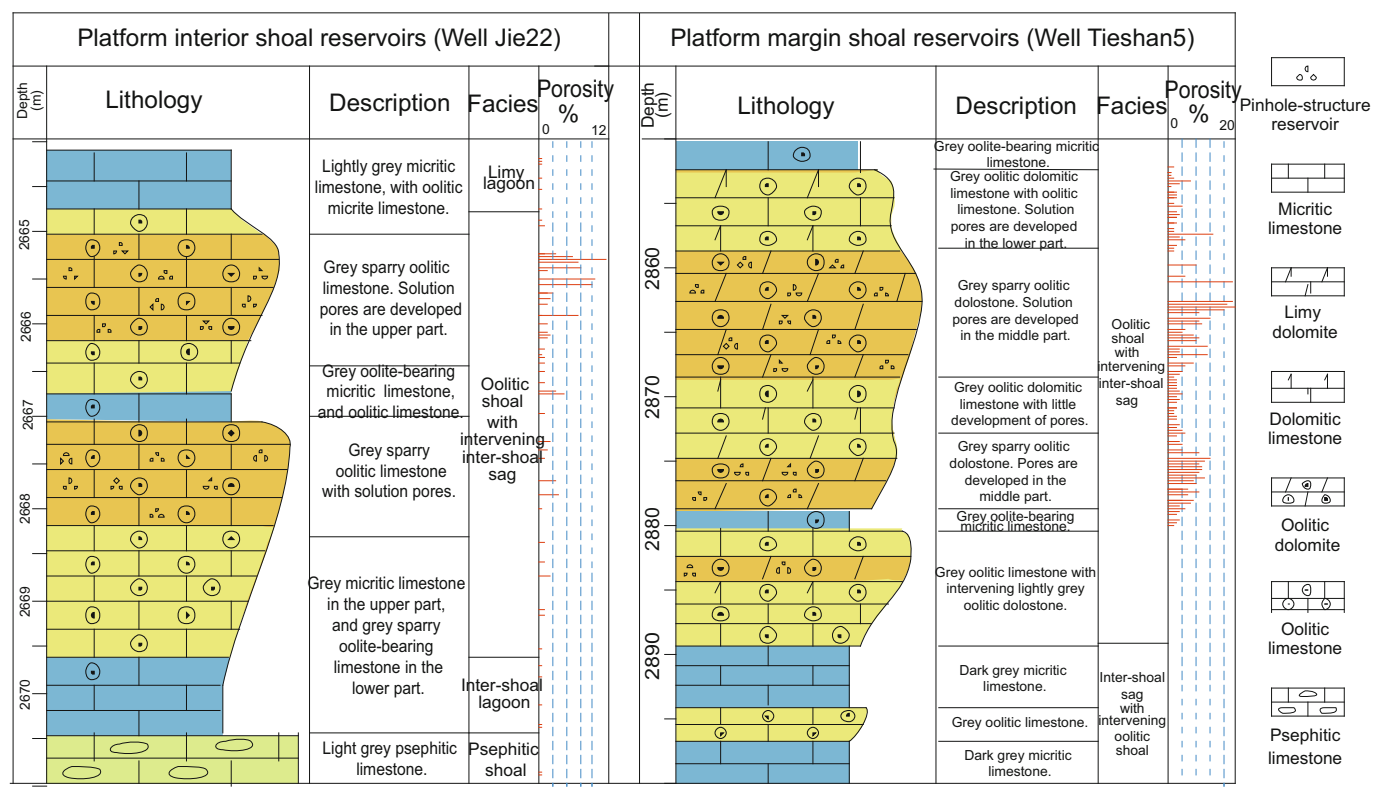

Fig. 2 Basic depositional features of oolitic shoal reservoirs in platform interior and platform margin locations. See the location of the wells in Fig. 1(b) 

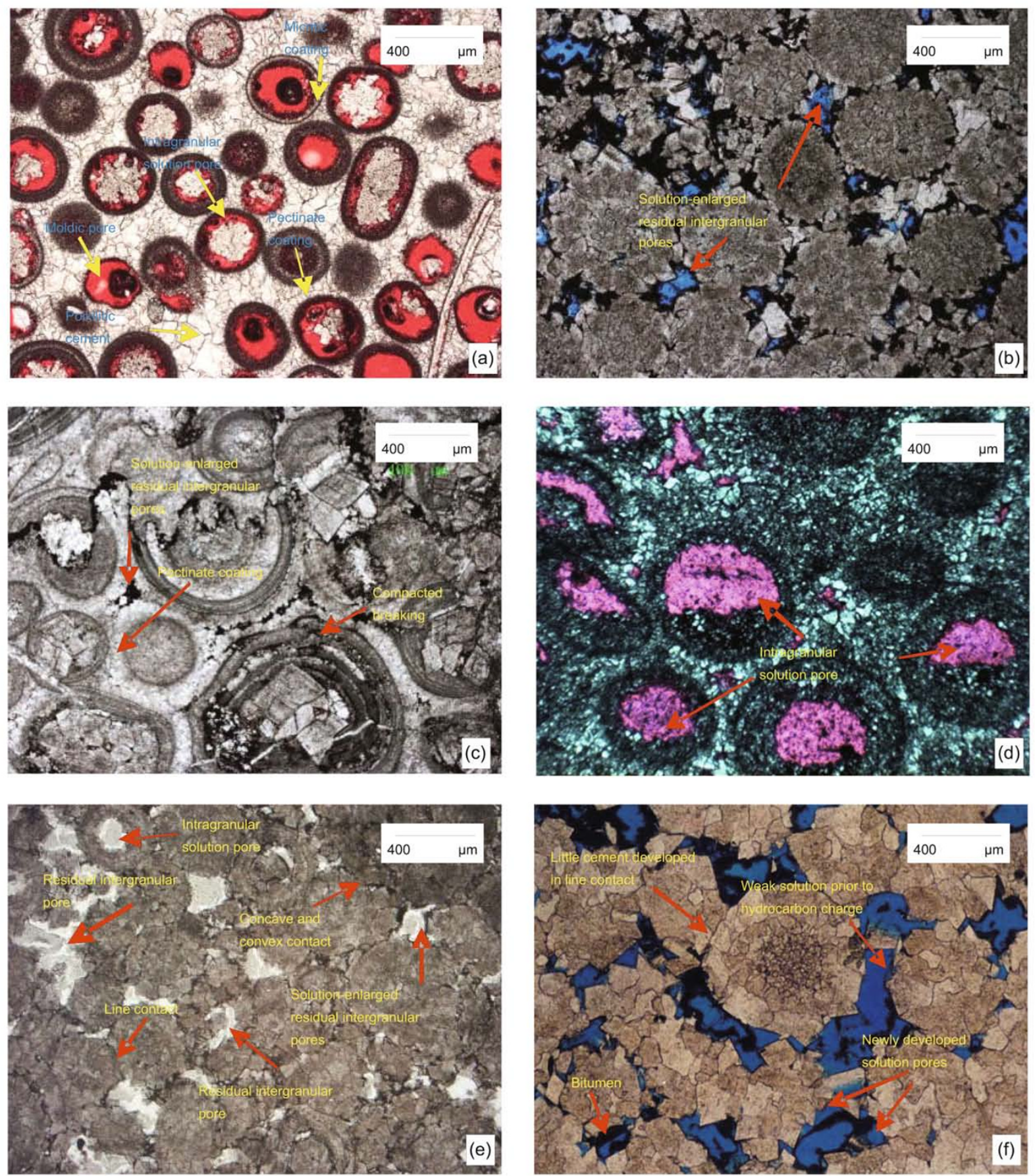

Fig. 3 Reservoir rock types, reservoir space and diagenetic features of oolitic shoal reservoirs in platform interior and platform margin locations. (a) Oolitic limestone with moldic and intergranular solution pores. Grains are not touching and have isolated contacts. Three generations of calcite cements are identified. Well Jie 22, $2683.2 \mathrm{~m}$, red-casting thin section. (b) Residual oolitic dolomite with intergranular solution pores with interstitial bitumen. Well Tieshan 5, $2865.0 \mathrm{~m}$, blue-casting thin section. (c) Oolitic limestone with compaction fractures. Residual intergranular pores are filled by bitumen. Well Tieshan 5, $2855.0 \mathrm{~m}$, thin section. (d) Oolitic dolomite with intergranular solution pores whose lower part is filled. Well Puguang 302-1, $5370.7 \mathrm{~m}$, red-casting thin section. (e) Oolitic dolomite with residual intergranular pores, solution-enlarged residual intergranular pores and intragranular solution pores. Oolites have line to concaveconvex contacts. Well Du 3, $4319.9 \mathrm{~m}$, rock thin section. (f) Oolitic dolomite with solution-enlarged residual intergranular pores. Oolites have line to concave-convex contacts. Well Luo 2, $3242.8 \mathrm{~m}$, blue-casting thin section

\subsubsection{Platform margin reservoirs}

Unlike those in the platform interior reservoirs, the rocks in the platform margin reservoirs are mainly composed of solution and residual oolitic dolomite, whose content can exceed $85 \%$ (Su et al, 2005) (Fig. 3(b)). In addition, some oolitic limestones can also be found (Fig. 3(c)). This implies that the rocks were deposited under a high-energy environment due to the high abundance of oolites. It is representative of the difference in depositional environment and paleogeography between the two types of shoals (Wei et al, 2004; Wang et al, 2008).

The content of oolites in this type of reservoir commonly 
ranges between $65 \%$ and $90 \%$, greater than that of the platform interior shoals. The particle size is generally $0.2-$ $1.5 \mathrm{~mm}$. Individual oolite dominate although complex oolites are also observed. The oolites are characterized by a residual structure due to intense dolomitization, and phantom concentric layers are preserved in some cases (Fig. 3(b)). Dolomite crystals are allotriomorphic and euhedralhypidiomorphic and are dominantly silt-sized to fine-grained (occasionally coarse-grained).

Similar to the platform interior shoals, the platform margin shoals also show shallowing- and coarsening-upward depositional sequences, while reverse graded bedding is also observed. The thickness and scale of individual shoals are greater than those of the platform interior shoals. For instance, the thickness is mostly greater than $2 \mathrm{~m}$, and even can reach up to $20 \mathrm{~m}$ (Fig. 2). In contrast to the platform interior shoals, reservoir space can develop not only at the top but also in the middle of an individual shoal (Fig. 2). The reservoir space is characterized by the development of residual intergranular pores because the thickness of individual shoals is large and the shoals have been mainly deposited in shallow water (Figs. 3(b), 3(e) and 3(f)). Intragranular solution pores and moldic pores (Fig. 3(d)) are developed in uplift areas, which is favorable for short period exposure during marine regressions. However, this type of porosity only occurs locally in comparison with the intergranular pores due to generally weak meteoric influence.

\subsection{Diagenesis}

\subsubsection{Platform interior reservoirs}

Diagenesis that has influenced the formation of the platform interior reservoirs generally includes compaction, calcite cementation and syngenetic to penecontemporaneous dissolution (Luo et al, 2009).

Compaction is commonly weak and, therefore, oolites mainly have point- or isolated-contacts (Fig. 3(a)). Oolite deformation and collapse caused by intense compaction was seldom observed.

Calcite cementation is intense in primary pore spaces, and three generations of calcite cements are identified. The early generation is of submarine origin and comprises micritic and microcrystalline calcites, fibrous calcite and bladed calcite. The micritic and microcrystalline calcites are commonly observed, with contents usually less than $1 \%$. They cover particle surfaces, forming a regular and isopachous cladding which occurs as a $2-20 \mu \mathrm{m}$ thick film visible as a dark line in thin-section (Fig. 3(a)). Fibrous calcite is commonly present in sparry oolitic limestone, forming pectinate and approximately isopachous rims surrounding oolites (Fig. 3(a)). The width of rim commonly ranges between 0.02 and $0.1 \mathrm{~mm}$, and the rims fill $3-5 \%$ of the pore space. The second generation of calcite cement is of meteoric origin. Crystal surfaces of the cement are well preserved with little obvious dissolution and the cement comfortably contacts with later coarse-grained calcite cement. The third generation of calcite cement was formed during burial diagenesis. Crystals are bright and thick with diameters greater than $0.1 \mathrm{~mm}$. It occurs in the centre of pores and fills residual pore space as single or poikilitic crystals, decreasing reservoir physical properties
(Fig. 3(a)).

Dissolution controls the reservoir formation, mainly including syngenetic to penecontemporaneous dissolution and burial dissolution (Luo et al, 2009). Moreover, the syngenetic to penecontemporaneous dissolution is more important than the burial dissolution, as supported by three lines of evidence.

(i) Dissolution is clearly controlled by lithologic composition and texture. As a result, oolites are commonly dissolved selectively, thereby forming moldic and intragranular solution pores (Fig. 3(a)). In contrast, nonselective solution pores that are related to micro-fractures and were formed during burial dissolution are rarely observed.

(ii) Dissolution is usually not controlled by fault and fracture systems but mainly by palaeo-topography and generally occurs in submarine highs and oolitic shoals (Luo et al, 2009).

(iii) Dissolution is related to the depositional sequence, which is characterized by shallowing-upward cycles. It is mainly developed in the middle and upper parts of individual shoals with little development in the lower part (Fig. 2). These selective features were not observed in nonselective burial dissolution. In addition, analysis shows that syngenetic to penecontemporaneous dissolution can increase the porosity by 5\%-20\% (Luo et al, 2009). In contrast, burial dissolution can only increase the porosity by $1 \%-3 \%$. Therefore, the contribution to the formation of the reservoirs from syngenetic to penecontemporaneous dissolution is large.

\subsubsection{Platform margin reservoirs}

Diagenesis controlling the formation of the oolitic shoal reservoirs in platform margin locations mainly includes compaction, pressure solution, calcite cementation, dolomitization and burial dissolution.

Compaction is relatively intense in general, as indicated by oolites having line or even concave-convex contacts (Fig. 3(e)). The compaction varies between limestones and dolostones. For instance, deformation, collapse and breakage of oolites were commonly observed in limestones (Fig. 3(c)), but not in dolostones. Oolitic limestones show intense compaction and pressure solution, providing material for burial cementation. As a consequence, primary intergranular pore spaces were seldom preserved. By contrast, oolitic dolostones are characterized by a moderate to strong compaction and weak pressure solution with less source of material for cementation, thereby leading to good preservation of primary intergranular pore space.

Cementation of primary pores is generally weak, with the development of two generations of cements. The first generation of cement comprises rim or isopachous, leafshaped and bladed calcites of submarine origin, 0.02-0.1 $\mathrm{mm}$ thick, which are subsequently replaced by dolomite and generally fill 5\%-10\% of primary pore space. The second generation of cement is a pectinate-like coating which significantly reduces primary intergranular pores and throats. In addition, the relatively strong compaction due to rapid sedimentation of overlying strata results in a grainsupported reservoir fabric. This further leads to a decrease in intergranular pore fluid exchange. As a consequence, later cements are poorly developed and vary in abundance between 
the limestones and dolostones. For limestones, shallow burial cements can be found easily in pore walls (Fig. 3(c)). The later cements of deep burial origin are also developed, filling early intragranular solution pores or residual intergranular pores. The content of burial cements in residual pores can exceed $25 \%$, which even can fully fill the residual pores in some cases. In contrast, in dolostones, the second generation of pectinate-coating cement generally fills $10 \%$ $15 \%$ of residual pores and the third generation of cement of deep burial origin is not developed. Thus, there is good preservation of residual intergranular pores (Figs. 3(e) and 3(f)).

Dolomitization is one of the key differences between the platform margin and platform interior reservoirs. The dolomitization takes place widely in the platform margin areas enriched in gypsum rocks, but not in the platform interior areas (Wang et al, 2007; Zheng et al, 2009; Huang et $\mathrm{al}, 2009)$. The minor dolomitization in the platform interior area (i.e., the central and western basin) is likely related to fluvial supply. This causes relatively low salinities of marine water, which is unfavourable for dolomitization. In contrast, the reason for the minor dolomitization in the eastern basin is different. It may be ascribed to a normal supply of marine water and weak evaporation (Zeng et al, 2007; Wang et al, 2007). Thus, dolomitization takes place in the northern and northeastern basin with a lenticular distribution in general (Wang et al, 2007). Dolomite crystals are mainly allotriomorphic to hypidiomorphic (Figs. 3(b) and 3(f)). Oolites in the dolostone have a residual structure including phantom concentric structures, indicating that they originated from limestones (Figs. 3(b) and 3(d)). Thus, the dolomitization is likely a replacement process with little volumetric change (Wang et al, 2007). In practice, the increase of reservoir porosity caused by dolomitization is very complex (Guo, 2010; Ma et al, 2011).

Dissolution in the platform margin shoal reservoirs is syngenetic to penecontemporaneous and burial in origin. This is similar to the platform interior reservoirs. However, the contribution to reservoir quality by burial dissolution is great, and syngenetic dissolution occurs only locally. Furthermore, there are two generations of burial dissolution. The first generation took place prior to bitumen emplacement, forming intergranular solution pores and intercrystalline solution pores in dolomite (Ma et al, 2011). Pore walls are not straight and bitumen coatings can be observed (Figs. 3(b) and 3(f)). The second generation of burial dissolution altered early solution pores, as indicated by the bitumen occurring in the central part (but not the margins) of the pores (Figs. 3(b) and 3(f)). Thus, pores inside the bitumen belt were most likely formed by the first generation of burial dissolution, while the pores outside the belt were formed by the second generation of burial dissolution. In addition, optical microscopy reveals that the crystal faces of some particulate cements in intergranular pores of shallow burial origin are straight with little influence of burial dissolution (Fig. 3(e)). Thus, the preserved primary pore space may have contributed significantly to porosity, and the burial dissolution may not have really changed the nature of the reservoirs.

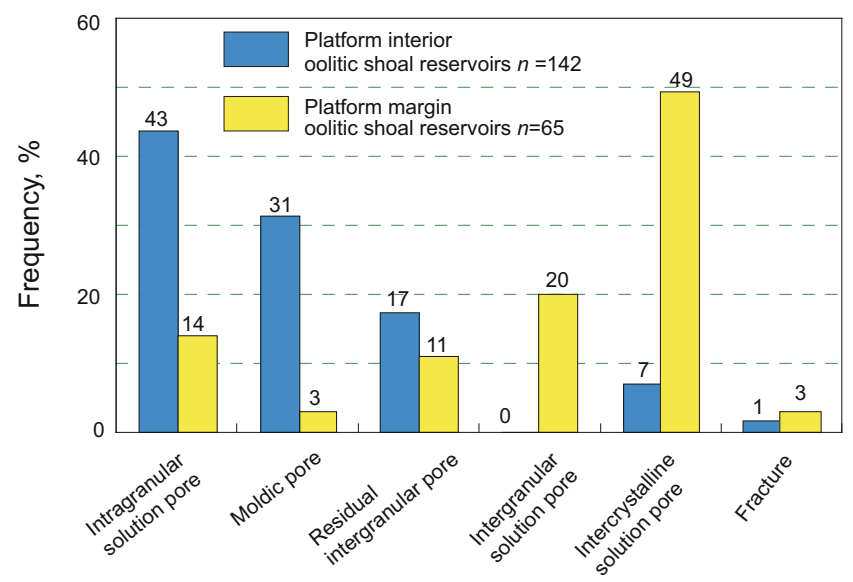

Fig. 4 Frequency of different types of reservoir space of oolitic shoal reservoirs in platform interior and platform margin locations

\subsection{Pore type and structure}

\subsubsection{Pore type}

Thin-section observation shows that there are six types of pore space in general: moldic, intragranular solution, residual intergranular, intercrystalline solution, intergranular solution and fracture-related pores. As shown in Fig. 4, for oolitic shoal reservoirs in platform interior locations, intragranular solution pores and moldic pores constitute $43 \%$ and $31 \%$ of the total porosity, respectively. By contrast, the contribution from the intergranular solution pores and residual intergranular pores is commonly less than $25 \%$ of the total porosity. For the oolitic shoal reservoirs in platform margin locations, the intergranular and intercrystalline solution pores dominate porosity, making up $50 \%$ and $20 \%$ of the total porosity, respectively. However, the intragranular solution and moldic pores are relatively minor in significance.

Thus, solution and moldic pores are the main pore types in the platform interior shoal reservoirs, while intergranular and intercrystalline solution pores are the principal pore types in the platform margin shoal reservoirs.

\subsubsection{Pore and throat structure}

The difference in reservoir pore and throat structure is well displayed by capillary pressure curves. The curve of the platform interior reservoirs shows a trend with relatively gentle slopes, and the values of displacement pressure (approximately $0.005 \mathrm{MPa}$ ) and median pressure (approximately $10 \mathrm{MPa}$ ) are high (Figs. 5(a) and 5(b)). In addition, the frequency band of pores and throats is narrow with good sorting (Figs. 5(a) and 5(b)). Thus, it can be inferred that narrow pore throats make a major contribution to permeability. Therefore, the platform interior reservoirs are characterized by small throats, relatively isolated pores and poor connectivity.

By contrast, capillary pressure curves of the platform margin reservoirs display a trend with relatively steep slopes, with low displacement pressure (approximately $0.003 \mathrm{MPa}$ ) and median pressure (approximately $1 \mathrm{MPa}$ ) (Figs. 5(c) and 5(d)). The frequency band of pores and throats is wide with relatively poor sorting (Figs. 5(c) and 5(d)), implying that coarse throats have a large contribution to permeability. Therefore, the platform margin reservoirs have coarser throats and better connectivity in comparison to the platform interior shoal reservoirs. 


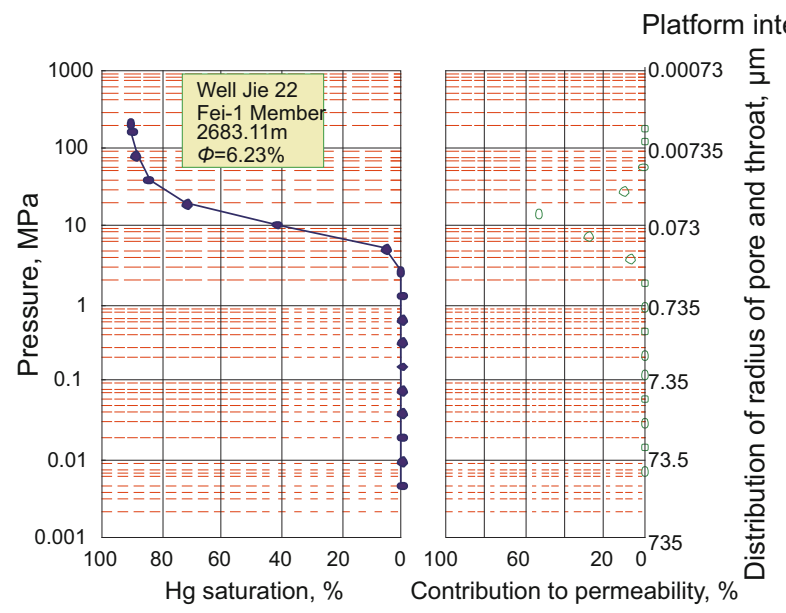

(a)

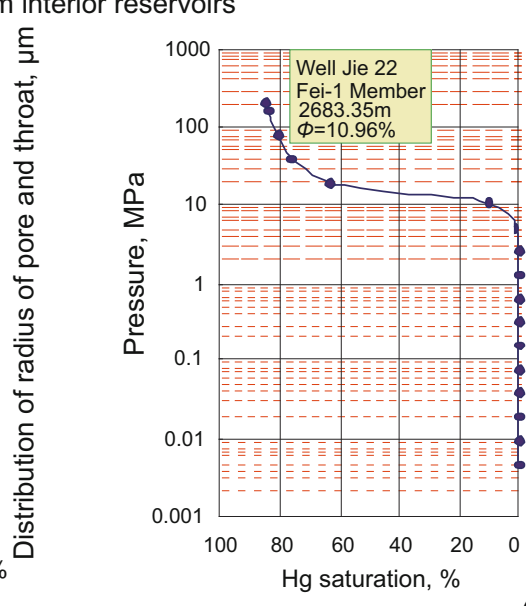

(b)

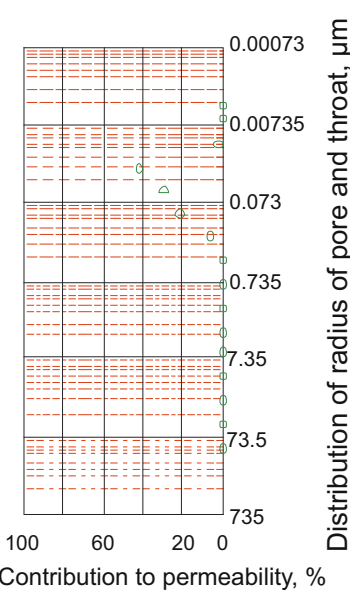

)

Platform margin reservoirs

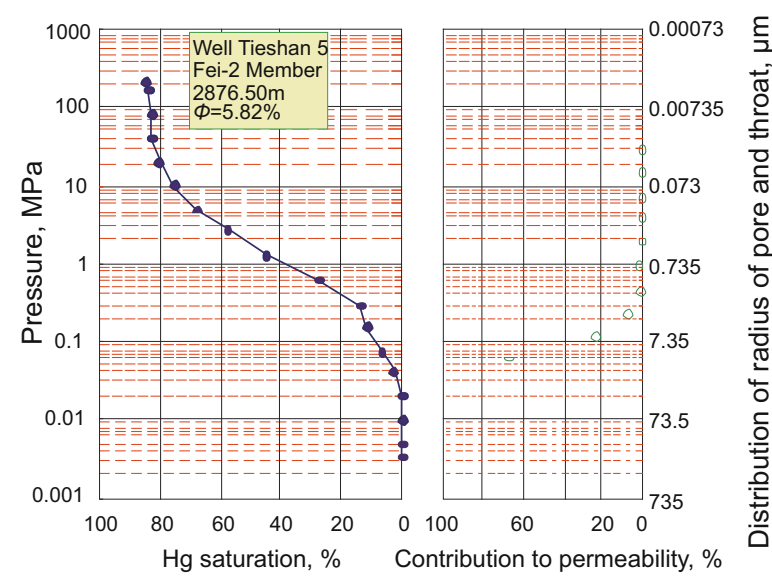

(c)
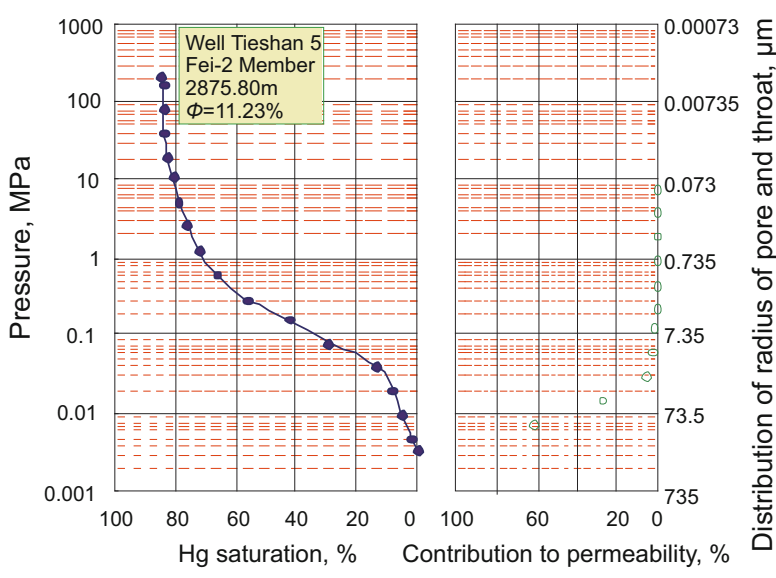

(d)

Fig. 5 Capillary pressure curve of oolitic shoal reservoirs in platform interior and platform margin locations. (a) Well Jie 22, 2683.11 m. (b) Well Jie 22, $2683.35 \mathrm{~m}$. (c) Well Tieshan 5, $2876.50 \mathrm{~m}$. (d) Well Tieshan 5, 2875.80 m. See the location of the wells in Fig. 1(b)

\subsection{Reservoir physical features}

The difference in physical features is mainly reflected in the distribution and relationship of porosity and permeability.

\subsubsection{Porosity}

Analyses show that the two types of reservoirs are both characterized by low porosities, with samples with porosity $<6 \%$ making up approximately $60 \%$ of the total samples and samples with relatively high porosity $(>9 \%)$ accounting for $17 \%-27 \%$ (Fig. 6(a)). The average porosity of the platform interior reservoirs $(6.3 \%)$ is lower than that of the platform margin reservoirs $(8.0 \%)$. Moreover, the porosity distribution has variations, as evidenced in the samples with porosity greater than 9\% in particular. As shown in Fig. 6(a), in the platform interior reservoirs, samples with porosity of $9 \%$ $12 \%$ and $>12 \%$ account for approximately $2 \%$ and $15 \%$ of the total samples, respectively. In contrast, in the platform margin reservoirs, the two values are approximately $10 \%$ and $17 \%$, respectively. Therefore, it is evident that the development of relatively high-quality reservoirs with porosity greater than $9 \%$ in the platform margin area is much higher than that in the platform interior area.

\subsubsection{Relationship between porosity and permeability}

The relationship between porosity and permeability varies between the two types of reservoirs, similar to the distribution of porosity discussed above. As shown in Fig. 6(b), there is a relatively linear trend for the relationship of porosity and permeability for the two types of reservoirs. This implies that they both belong to pore-type reservoirs. Difference mainly occurs in the pore-throat distribution and the indicated porethroat structure. For the platform interior reservoirs, most data points plot in the zone with relatively low porosities. By contrast, for the platform margin reservoirs, the data points are distributed in the zone with relatively high porosities. In addition, the linear trend of the platform margin reservoirs is better than that of the platform interior reservoirs, indicating a coarse and narrow pore-throat structure for the margin and interior reservoirs, respectively. This is consistent with the capillary pressure curves (Fig. 5).

\subsection{Summary}

Based on the above results, we summarized the differences of basic reservoir features between the platform margin and platform interior locations in Table 1. 


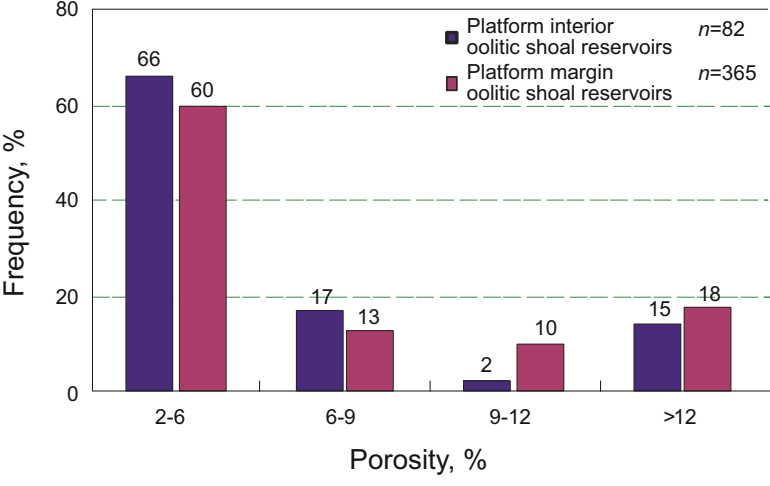

(a)

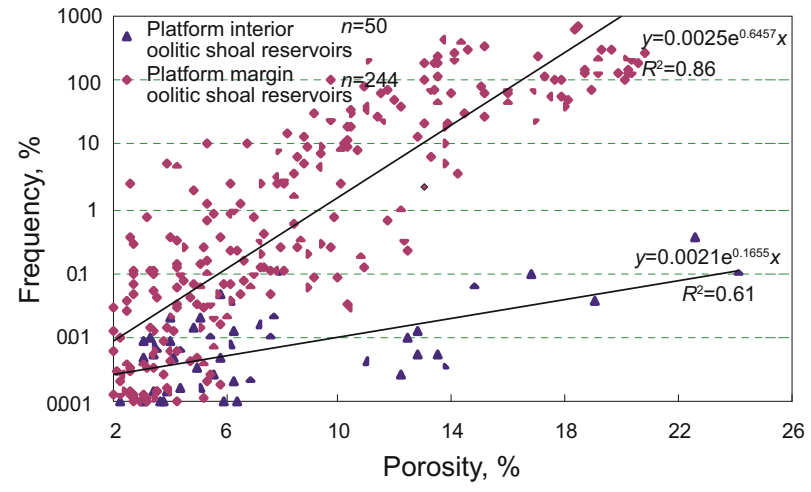

(b)

Fig. 6 Physical properties of oolitic shoal reservoirs in platform interior and platform margin locations. (a) Distribution of porosity. (b) Relationship between porosity and permeability

Table 1 Comparison of basic features of oolitic shoal reservoirs between platform interior and platform margin locations

\begin{tabular}{|c|c|c|c|}
\hline & & Platform interior oolitic shoal reservoirs & Platform margin oolitic shoal reservoirs \\
\hline \multirow{5}{*}{$\begin{array}{l}\text { Depositional } \\
\text { characteristics }\end{array}$} & $\begin{array}{l}\text { Developing } \\
\text { environment }\end{array}$ & $\begin{array}{l}\text { Topographic highs characterized by moderate to high } \\
\text { energy environments with an energy interface } 0-2 \mathrm{~m} \text {. }\end{array}$ & $\begin{array}{l}\text { Topographic highs characterized by high } \\
\text { energy environments with an energy } \\
\text { interface } 0-20 \mathrm{~m} \text {. }\end{array}$ \\
\hline & Lithologic type & $\begin{array}{l}\text { Mainly composed of oolitic limestone with the } \\
\text { content of oolite } 50 \%-85 \% \text { and grain diameter } \\
\text { of generally } 0.2-1.0 \mathrm{~mm} \text {. }\end{array}$ & $\begin{array}{c}\text { Mainly composed of sparry oolitic } \\
\text { dolostone with some oolitic limestones. Content of } \\
\text { oolite is } 65 \%-90 \% \text { and grain } \\
\text { diameter of generally } 0.2-1.5 \mathrm{~mm} \text {. }\end{array}$ \\
\hline & $\begin{array}{l}\text { Depositional } \\
\text { sequence }\end{array}$ & Shallowing upward. & Shallowing upward. \\
\hline & Thickness and size & $\begin{array}{l}\text { Thickness of individual shoal bodies is }<2 \mathrm{~m} \\
\text { and cumulative thickness is }<20 \mathrm{~m} .\end{array}$ & $\begin{array}{l}\text { Thickness of individual shoal bodies is } \\
2-20 \mathrm{~m} \text { and cumulative thickness is }>20 \mathrm{~m} \text {. }\end{array}$ \\
\hline & Distribution & Lenticular or isolated. & Banded or beaded. \\
\hline \multirow{5}{*}{ Diagenesis } & Compaction & Weak with grains in point contact. & Strong with grains in line or concavo-convex contact. \\
\hline & Pressure solution & Strong. Stylolite is commonly observed. & $\begin{array}{l}\text { Strong and weak for limestone and } \\
\text { dolostone, respectively. }\end{array}$ \\
\hline & Cementation & $\begin{array}{l}\text { Strong and extensive. Primary pore space } \\
\text { is poorly preserved. }\end{array}$ & $\begin{array}{l}\text { Relatively strong and not too extensive. } \\
\text { Some primary pore space is preserved. }\end{array}$ \\
\hline & Dissolution & $\begin{array}{l}\text { Early meteoric freshwater dissolution dominating } \\
\text { with less burial dissolution. }\end{array}$ & $\begin{array}{l}\text { Early meteoric freshwater dissolution } \\
\text { and burial dissolution. }\end{array}$ \\
\hline & Dolomitization & Weak or little. & $\begin{array}{l}\text { Strong with evident early } \\
\text { stage dolomitization. }\end{array}$ \\
\hline \multirow[b]{2}{*}{ Reservoir space } & Pore type & Intragranular solution and moldic pores. & $\begin{array}{l}\text { Intergranular solution, intercrystalline } \\
\text { solution and residual intergranular pores. }\end{array}$ \\
\hline & $\begin{array}{l}\text { Structure of } \\
\text { pore and throat }\end{array}$ & $\begin{array}{l}\text { A trend with relatively gentle slope in capillary } \\
\text { pressure curve and high displacement and median } \\
\text { pressures. Good sorting of pores and throats. Narrow } \\
\text { throats make major contribution to permeability. }\end{array}$ & $\begin{array}{l}\text { A trend with relatively steep slope in capillary } \\
\text { pressure curve and relatively low displacement } \\
\text { and median pressures. Relatively poor sorting } \\
\text { of pores and throats. Coarse throats make major } \\
\text { contribution to permeability. }\end{array}$ \\
\hline \multirow{3}{*}{$\begin{array}{l}\text { Physical } \\
\text { property }\end{array}$} & Porosity & $\begin{array}{l}\text { Mainly low porosity }(<6 \%) \text {. Samples with high } \\
\text { porosity }(>9 \%) \text { less than } 20 \% \text { of the total. }\end{array}$ & $\begin{array}{l}\text { Low-middle porosity with }>9 \% \\
\text { porosity up to } 27 \% \text { of the total. }\end{array}$ \\
\hline & Permeability & $\begin{array}{l}\text { Mainly low permeability. Samples with }>0.1 \mathrm{mD} \\
\text { permeability less than } 10 \% \text { of the total. }\end{array}$ & $\begin{array}{l}\text { Low to middle permeability. Samples } \\
\text { with }>0.1 \mathrm{mD} \text { permeability greater } \\
\text { than } 60 \% \text { of the total. }\end{array}$ \\
\hline & $\begin{array}{l}\text { Relationship } \\
\text { between porosity } \\
\text { and permeability }\end{array}$ & $\begin{array}{l}\text { Linear correlation. Data mostly in low permeability } \\
\text { zone. Isolated pore-type reservoir. }\end{array}$ & $\begin{array}{l}\text { Linear correlation. Data mostly } \\
\text { in high permeability zone. Pore-type } \\
\text { reservoir with relatively good connectivity. }\end{array}$ \\
\hline
\end{tabular}




\section{Origins of reservoirs}

The difference of basic reservoir features listed in Table 1 implies that the formation of the reservoirs varies between the platform interior and platform margin locations, controlled by a combination of primary depositional and secondary diagenetic factors.

\subsection{Platform interior reservoirs}

The oolitic shoal reservoirs in platform interior locations are mainly developed on topographic highs with moderate to high energy settings. The reservoir rock is mainly composed of oolitic limestones, whose thickness is not great $(<2 \mathrm{~m}$ for individual shoal bodies). Intragranular solution and moldic pores caused by selective meteoric dissolution commonly occur at the top of the shallowing-upward depositional sequences. This implies that the disturbing depth of the wave base within the platform is relatively shallow and, thus, the depositional environment is characterized by a low energy in general and the high-energy depositional environment favorable for the development of oolitic shoals is limited (e.g., those structural highs). The water depth was less than $2 \mathrm{~m}$ and, thus, the shoal bodies were frequently influenced by meteoric water due to vertical aggradation and equivalent regression. The evolution of the reservoirs can be generally divided into four stages; deposition, exposure, shallow burial and deep burial (Fig. 7).

In the deposition stage, the original intergranular porosity of an oolitic shoal was approximately 40\% (Heydari, 2000), which decreased to $35 \%$ under the influence of the first generation of submarine cementation.

In the exposure stage, meteoric dissolution and cementation occur almost simultaneously. In changing reservoir porosity, the dissolution (increasing porosity by approximately 35\%) exceeds cementation (decreasing porosity by approximately 10\%-20\%). Thus, the reservoir pore space is enlarged in general, with the net increase being $15 \%-25 \%$ and the final porosity becoming up to $60 \%$. The pore types mainly include intergranular and intragranular solution pores, which are supported dominantly by consolidated grains and coated cements.

In the shallow burial stage during the Middle-Late Indosinian period, the compaction occurred due to the aggradation of overlying sediments, and was weak because the shoal bodies were thin. As a result, the decrease of porosity caused by compaction was small. During this stage, burial cementation had a relatively minor impact on reservoir porosity. Monocrystalline or poikilitic calcite cements of burial origin filled residual primary intergranular and syngenetic solution pore spaces. As a consequence, the original primary intergranular pores were rarely preserved, and the relatively isolated intragranular solution and moldic pores were partially preserved. The porosity of most reservoir rocks decreased to $<15 \%$ after this stage.

In the deep burial stage after the Late Indosinian period, diagenesis mainly included fracturing and burial solution, and can be further divided into two sub-stages. The first sub-stage is characterized by dissolution and alteration caused by fluids generated during the thermal maturation of hydrocarbon source rocks. The second sub-stage is different in terms of the fluid source. Sulfate minerals (e.g., gypsum) were reduced by hydrocarbons, thereby generating $\mathrm{H}_{2} \mathrm{~S}$ and $\mathrm{CO}_{2}$ during the thermo-chemical sulphate reduction. Then, $\mathrm{H}_{2} \mathrm{~S}$ dissolves in water, forming hydrosulfuric acid, while $\mathrm{CO}_{2}$ forms carbonic acid (Wang et al, 2007). The mixture of these two types of acidic fluids dissolved carbonate rocks. However, the net increase of porosity due to the burial dissolution is commonly less than $5 \%$. This is because the pores here were isolated before deep burial and, therefore, there is little migration pathway for burial fluids.

\subsection{Platform margin reservoirs}

In contrast to the platform interior reservoirs, the platform margin reservoirs developed in relatively high energy environments. The lithology includes not only oolitic limestones like the platform interior reservoirs, but also oolitic dolostones. The shoal bodies are relatively thick, and even exceed $20 \mathrm{~m}$. Meteoric dissolution only occurs at the top of shoal bodies in some cases, accounting for a limited part of the reservoir. Thus, it can be indicated that the depositional environment is characterized by a relatively high energy and the disturbing depth of the wave base is big. Water favorable for the development of oolitic shoals is deep and the vertical accommodation space can reach 20 $\mathrm{m}$. As a result, the shoal is commonly underwater for a long time with occasional influence by meteoric water; this is favorable for the dolomitization. The reservoir evolution can be divided into two sub-types according to shoal thickness, i.e., thin $(<3 \mathrm{~m})$ and thick shoals $(\geq 3 \mathrm{~m})$. For thin shoals, the reservoir evolution is similar to that of the platform interior reservoirs. However, it is developed only to a limited extent. The platform margin shoal reservoirs are characterized by the predominant development of thick shoal bodies. Thus, the reservoir evolution of the thick shoal bodies is discussed here in emphasis. Similar to the platform interior reservoirs, the evolution of the platform margin reservoirs can also be divided into four stages; however, their evolution and origins are different (Fig. 7).

In the deposition stage, the original intergranular porosity in high-energy oolitic limestone was about 40\% (Heydari, 2000), which lost 5\%-10\% to become 30\%-35\% under the influence of the first generation of submarine cementation.

In the exposure stage, meteoric dissolution and cementation is weak and, thus, the increase of porosity is not obvious being only $2 \%-3 \%$. In addition, dolomitization is intense but does not result in major volumetric change (Wang et al, 2007). Thus, the dolomitization has minor impacts on reservoir porosity. The porosity does not change significantly during this stage, still at approximately $35 \%$ in general.

In the shallow burial stage during the Middle-Late Indosinian period, the compaction was relatively strong due to the rapid aggradation of overlying sediments and thick shoal bodies, and reservoir types started to differentiate as dolostones and limestones have different anti-compaction ability (Schmoker and Halley, 1982). The limestones are severely compacted, leading to pressure solution and the development of stylolites. In addition, supersaturated fluids of pressure solution origin cement residual pore 


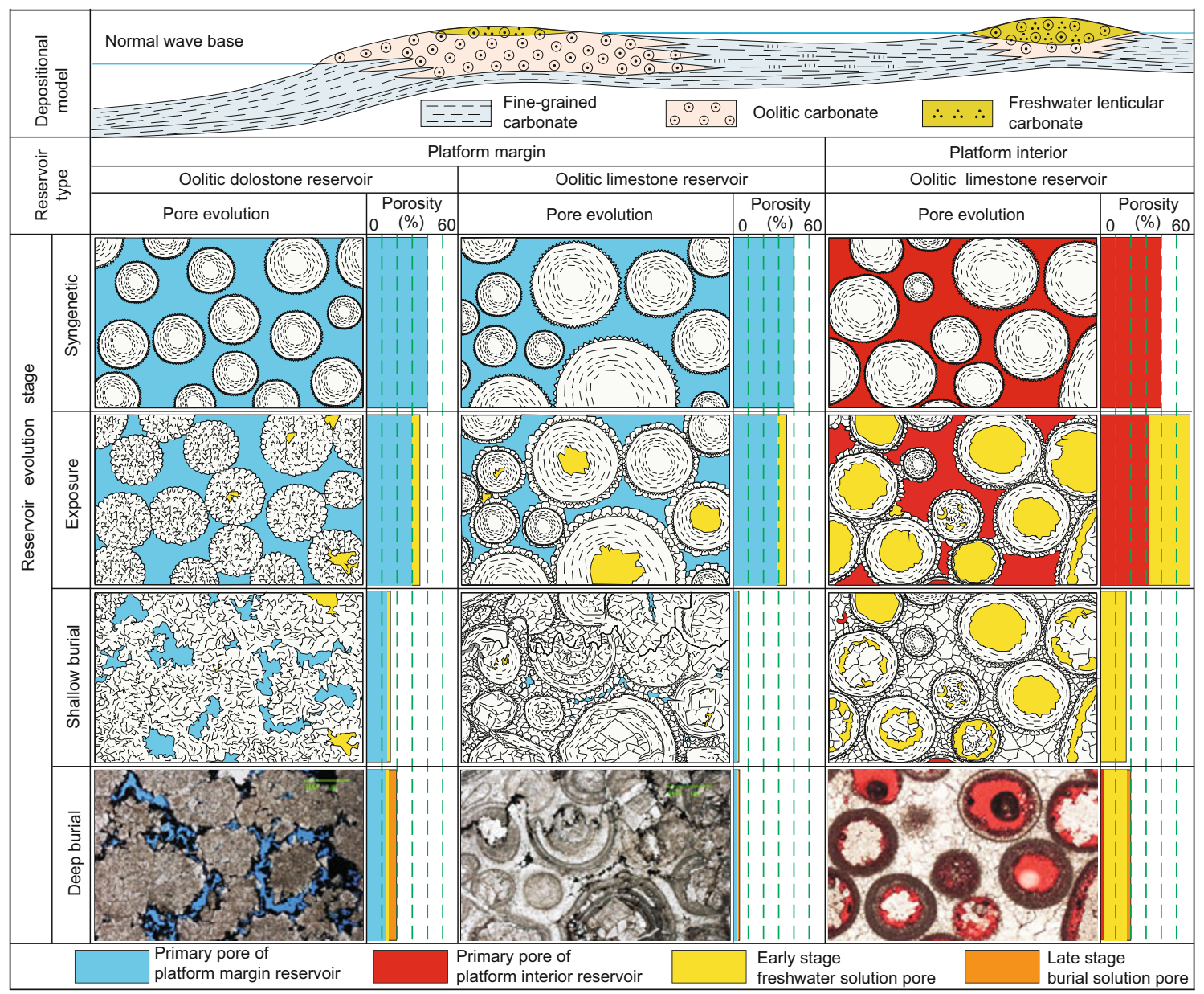

Fig. 7 Sketch map showing evolution and origin of oolitic shoal reservoirs in platform interior and platform margin locations

spaces. Thus, the reservoir porosity largely decrease and is accompanied by compaction, fragmentation and dense packing of oolites. In contrast, for the oolitic dolostones, the compaction is relatively weak due to strong anticompaction ability in comparison with the limestones and, thus, the oolites are not crushed and have line to concaveconvex contacts. Contemporaneous cementation occurs only in the walls of residual intergranular pores, thereby leading to the termination of fluid exchange. Hence, the residual intergranular pore space is preserved. After this shallow burial stage, the porosity of the limestone reservoirs is only $2 \%-3 \%$, while that of the dolostone reservoirs can be $10 \%-15 \%$ due to relatively good preservation.

In the deep burial stage after the Late Indosinian period, structural fracturing and burial dissolution took place (Liu et al, 2008). Like in the platform interior reservoirs, there are also two generations of burial dissolution, which, however, are more intense (in particular for the dolostone reservoirs). This is because the dolostone reservoirs have better pathway systems for fluid migration and alteration than the limestone reservoirs after their evolution in the shallow burial stage as discussed above. Primary residual pores may be enlarged under the influence of the burial fluids, forming solution pores and vugs. The porosity usually increases by $3 \%-10 \%$ and even more than $10 \%$ in some cases.

\subsection{Difference of reservoir origins}

For the platform interior reservoirs, the contribution to the porosity from the early meteoric dissolution is more than $70 \%$, while that of the later fracturing and burial dissolution is generally less than $20 \%$. Thus, the origin of the reservoirs is early freshwater solution, while the structural fracturing and burial dissolution have relatively limited impacts.

In contrast, the thick oolitic dolomites are the best rock type of the platform margin oolitic reservoirs. The preservation of the primary pore space is important due to the anti-compaction nature of the dolomite, which can contribute to the total porosity at approximately $60 \%$. The porosity caused by burial dissolution generally makes up $20 \%$ $30 \%$ of the total porosity because the dolostone reservoirs have a good fluid exchange during the burial stage. In some cases, this contribution can exceed $30 \%$. Therefore, the final porosity is mainly caused by the preservation of primary intergranular porosity and burial dissolution. This reservoir origin is different from that of the platform interior reservoirs.

\section{Conclusions}

The oolitic shoal reservoir is an important type for carbonate hydrocarbon exploration and exploitation worldwide, and can be divided into two basic types; the 
platform interior and platform margin reservoirs. In the Sichuan Basin of southwest China, the Lower Triassic Feixianguan Formation has both types of reservoirs, whose basic features and origins were compared in detail in this paper for the first time.

1) The two types of reservoirs vary remarkably in reservoir basic features, including depositional characteristics, diagenesis, reservoir space and physical property. The platform interior reservoirs are generally deposited in a moderate-high energy environment. The deposited limestones are weakly compacted, strongly cemented and mainly dissolved by meteoric water. Thus, the reservoir space is mainly composed of intragranular solution and moldic pores, with low porosity $(<6 \%)$ and permeability $(<0.1 \mathrm{mD})$ dominating. The pore-throat structure is narrow.

2) In contrast, the platform margin reservoirs are deposited in a relatively higher energy environment than the interior reservoirs. The deposited rocks are mainly dolostones with some limestones, different from the interior reservoirs. They are strongly compacted and weakly cemented. As a result, some primary intergranular pores are preserved. Both meteoric and burial solution take place. Thus, the reservoir space is complex, mainly including intergranular solution pores, intercrystalline solution pores and residual intergranular pores. They have relatively higher physical properties ( $>9 \%$ porosity and $>0.1 \mathrm{mD}$ permeability) and better pore-throat structure than the interior reservoirs.

3) The origin of the reservoirs is a complex process influenced by primary deposition and later diagenesis. For the platform interior reservoirs, the early meteoric freshwater solution, weak compaction and cementation have important impacts on the reservoir formation. In contrast, the factors that affect the formation of the platform margin reservoirs include dolomitization, preservation of primary pores and burial dissolution. As to the ultimate influencing factor, it is early meteoric freshwater solution for the platform interior reservoirs ( $>70 \%$ contribution to the total porosity), while is the preservation of primary pores (approximately $60 \%$ contribution to the total porosity) superimposed by burial dissolution (approximately $20 \%-30 \%$ contribution to the total porosity) for the platform margin reservoirs.

\section{Acknowledgements}

We would like to thank Christopher Tiratsoo for assistance with the English and valuable suggestions for the improvements of an early version of this manuscript. We also show sincere thanks to the editor and two anonymous reviewers for their constructive comments. PetroChina Southwest Oil and Gas Field Company is thanked for permission to publish this paper. This work was jointly funded by the National Basic Research Development Program (973 project, Grant No. 2012CB214803), PetroChina Youth Innovation Foundation (Grant No. 2011D-5006-0105) and Key Subject Construction Project of Sichuan Province, China (Grant No. SZD 0414).

\section{References}

Bliefnick D M and Kaldi J G. Pore geometry: control on reservoir properties, Walker Creek Field, Columbia and Lafayette counties, Arkansas. AAPG Bulletin. 1996. 80(7): 1027-1044

Borkhataria R, Aigner T, Pöppelreiter M C, et al. Characterisation of epeiric "layer-cake" carbonate reservoirs: Upper Muschelkalk (Middle Triassic), the Netherlands. Journal of Petroleum Geology. 2005. 28(2):119-146

Carnell A J H and Wilson M E J. Dolomites in SE Asia—varied origins and implications for hydrocarbon exploration. Geologcal Society of London, Special Publication. 2004. 235: 255-300

Chen Z Q. Discussion on gas exploration of Feixianguan Formation in the Lower Triassic of Sichuan Basin. Acta Petrolei Sinica. 2007. 28(5): 12-26 (in Chinese)

Eichenseer H T, Walgenwitz F R and Biondi P J. Stratigraphic control on facies and diagenesis of dolomitized oolitic siliciclastic ramp sequences (Pinda Group, Albian, offshore Angola). AAPG Bulletin. 1999. 83(11): 1729-1758

Fan J S. Characteristics of carbonate reservoirs for oil and gas fields in the world and essential controlling factors for their formation. Earth Science Frontiers. 2005. 12(3): 23-30 (in Chinese)

Guo T L. Diagenesis of the Feixianguan oolitic shoal reservoirs in the northeastern Sichuan Basin-examples from Xuanhan-Daxian and Yuanba areas. Oil and Gas Geology. 2010. 31(5): 620-631 (in Chinese)

Heydari E. Porosity loss, fluid flow, and mass transfer in limestone reservoirs: Application to the Upper Jurassic Smackover Formation, Mississippi. AAPG Bulletin. 2000. 84(1): 100-118

Huang S J, Tong H P, Liu L H, et al. Petrography, geochemistry and dolomitization mechanisms of Feixianguan dolomites in Triassic, NE Sichuan, China. Acta Petrologica Sinica. 2009. 25(10): 13631372 (in Chinese)

Keith B D and Zuppann C W. Mississippian oolites and petroleum reservoirs in the United States-an overview. In: Mississippian Oolites and Modern Analogs. AAPG Studies in Geology. 1993. 35: $1-12$

Liu S G, Huang W M, Zhang C J, et al. Research status of dolomite genesis and its problems in Sichuan Basin. Lithologic Reservoirs. 2008. 20(2): 6-15 (in Chinese)

Luo B, Tan X C, Liu H, et al. Genetic mechanism analysis on oolitic reservoir of Lower Triassic Feixianguan Formation in the Shunan area, Sichuan Basin. Acta Sedimentologica Sinica. 2009. 27(3): 404409 (in Chinese)

Luo P, Zhang J, Liu W, et al. Characteristics of marine carbonate hydrocarbon reservoirs in China. Earth Science Frontiers. 2008. 15(1): 36-39 (in Chinese)

Ma Y S, Cai X Y and Zhao P R. The research status and advances in porosity evolution and diagenesis of deep carbonate reservoir. Earth Science Frontiers. 2011. 18(4): 181-192 (in Chinese)

Ma Y S, Guo X S, Guo T L, et al. Discovery of the large-scale Puguang gas field in the Sichuan Basin and its enlightenment for hydrocarbon prospecting. Geological Review. 2005. 25(4): 476-480 (in Chinese)

Ma Y S, Guo X S, Guo T L, et al. The Puguang gas field: New giant discovery in the mature Sichuan Basin, southwest China. AAPG Bulletin. 2007. 91(5): 627-643

Ran L H, Chen G S and Xu R F. Discovery and exploration of Luojiazhai Gas Field, Sichuan Basin. Marine Origin Petroleum Geology. 2005. 10(1): $43-47$ (in Chinese)

Ronchi P, Ortenzi A, Borromeo O, et al. Depositional setting and diagenetic processes and their impact on the reservoir quality in the late Visean-Bashkirian Kashagan carbonate platform (Pre-Caspian Basin, Kazakhstan). AAPG Bulletin. 2010. 94(9): 1313-1348

Schauer M and Aigner T. Cycle stacking pattern, diagenesis and reservoir geology of peritidal dolostones, Trigonodus-dolomite, Upper Muschelkalk (Middle Triassic, SW Germany). Facies. 1997. 37(1): 99-114 
Schmoker J W and Halley R B. Carbonate porosity versus depth: A predictable relation for south Florida. AAPG Bulletin. 1982. 66(5): 2561-2570

Su L P, Luo P, Hu S R, et al. Diagenesis of oolitic bank of the Feixianguan Formation of Lower Triassic in Luojiazhai Gas Field, Northeastern Sichuan Province. Journal of Palaeogeography. 2004. 6(2): 182-190 (in Chinese)

Su L P, Luo P, Luo Z, et al. Characteristics of Feixianguan Formation oolitic shoal reservoirs in Northeast Sichuan Basin. Natural Gas Industry. 2005. 25(6): 14-17 (in Chinese)

Tong C G. Tectonic Evolution and Hydrocarbon Accumulation in the Sichuan Basin. Beijing: Geological Publishing House. 1992. 19-37 (in Chinese)

Wang Y G, Hong H T, Xia M L, et al. Exploration of reef-bank gas reservoirs surrounding Permian and Triassic troughs in Sichuan Basin. Natural Gas Industry. 2008. 28(1): 22-27 (in Chinese)

Wang Y G, Wen Y C, Hong H T, et al. Diagenesis of Triassic Feixianguan Formation in Sichuan Basin, Southwest China. Acta Sedimentologica Sinica. 2007. 25(6): 831-839 (in Chinese)

Wei G Q, Chen G S, Yang W, et al. Sedimentary system of platformal trough of Feixianguan Formation of Lower Triassic in Northern Sichuan Basin and its evolution. Acta Sedimentologica Sinica. 2004. 22(2): 254-260 (in Chinese)

Wei G Q, Xie Z Y, Liu M C, et al. Favourable reservoir facies tracts in the Changxing-Feixianguan formations of Sichuan Basin. Natural Gas Industry. 2009. 29(9): 35-38 (in Chinese)

Westphal H, Eberli G P, Smith L B, et al. Reservoir characterization of the Mississippian Madison Formation, Wind River Basin, Wyoming. AAPG Bulletin. 2004. 88(4): 405-432
Yang X P, Zhao W Z, Cao H, et al. Formation and distribution of Triassic Feixianguan oolitic bank favourable reservoir in the NE Sichuan Basin. Petroleum Exploration and Development. 2006. 33(1): 17-21 (in Chinese)

Zeng W, Huang X P, Yang Y, et al. The origin and distribution of dolostone in Feixianguan Formation in Lower Triassic series, Northeast Sichuan. Journal of Southwest Petroleum University. 2007. 29(1): 19-22 (in Chinese)

Zhang B Q and $\mathrm{Hu}$ M Y. Diagenesis and porosity evolution characteristics of Lower Triassic Feixianguan Formation in the Eastern Sichuan and Western Hubei. Journal of Oil and Gas Technology. 2008. 30(6): 9-14 (in Chinese)

Zhao W Z, Luo P, Chen G S, et al. Origin and reservoir rock characteristics of dolostones in the Early Triassic Feixianguan Formation, NE Sichuan Basin, China: Significance for future gas exploration. Journal of Petroleum Geology. 2005. 28(1): 83-100

Zhao W Z, Wang Z C and Wang Y G. Formation mechanism of highly effective gas pools in the Feixianguan Formation in the NE Sichuan Basin. Geological Review. 2006. 52(5): $708-717$ (in Chinese)

Zhao Z J, Fan G Z, Wu X N, et al. Reservoir types, exploration domains and exploration strategy of marine carbonates in China. Marine Origin Petroleum Geology. 2007. 12(1): 1-11 (in Chinese)

Zheng R C, Wen H G, Zheng C, et al. Genesis of dolostone of the Feixianguan Formation, Lower Triassic in the NE Sichuan Basin: Evidences from rock structure and strontium content and isotopic composition. Acta Petrologica Sinica. 2009. 25(10): 2459-2468 (in Chinese)

(Edited by Hao Jie) 